\title{
Industrial Waste Valorization to Produce Eco-materials for Construction Applications
}

\author{
Isabel Brás, Ricardo Almeida, P. Costeira Silva, and Luís Marques
}

\begin{abstract}
The increasing concerns regarding buildings' sustainability throughout their lifecycle is a decisive criterion for systems and materials selection, both for new construction and rehabilitation. The valorization of regional industries wastes, namely fly ashes and pulp mill sludge, in bonding and rendering mortars, partially replacing the mortar's binder, was tested. The main goal was to study the ability to minimize the production costs and the environmental impact of mortar production with the development of an eco-material.

To evaluate the wastes and cement chemical characteristics, leaching procedures were performed, previous to mortar manufacture. Mortars, with and without waste incorporation, were made allowing comparative analyses of the adhesive capacity of the materials under study. The mechanical strength was also evaluated by compressive and flexural strength tests at different ages. Chemical stability of mortars was tested at 28-day samples.

Results showed that the incorporation of small amounts of ashes from biomass and lime mud from a paper mill in the mortars did not decrease significantly the mechanical strength and had no negative effect in the chemical behavior of the mixtures.
\end{abstract}

Index Terms-Ashes, eco-materials, mortar, pulp mill sludge, waste valorization.

\section{INTRODUCTION}

Eco-materials are categorized to have good characteristics as well as performances, decreasing the environmental impact in the overall life cycle [1]. The replacement of conventional raw materials by industrial wastes became an important feature in eco-materials development once reduce the need of wastes disposal and the decrease of scarce resources utilization. Several materials have been studied with this purpose, like agro waste (baggage, rice and wheat straw and husk, saw mill waste, ground nut shell) or industrial waste (coal combustion residues, steel slag, bauxite red mud, construction debris, waste gypsum, lime sludge, lime stone waste, broken glass and ceramics, marble processing residues, kiln dust) [2]. The utilization of fly ashes and paper mill has been reported for several proposes with good results [3]-[7].

The new and alternative building construction materials developed using agro and industrial wastes have ample scope for introducing new building components that will reduce to an extent the environmental and financial costs of building materials.

The incorporation of waste in mortar or concrete is today a

Manuscript received February 16, 2015; revised September 1, 2015.

The authors are with the Escola Superior de Tecnologia, Portugal (e-mail: ipbras@estv.ipv.pt, ralmeida@estv.ipv.pt, pcosteira@estv.ipv.pt, luismarques0@ hotmail.com). reality under construction. When this practice is used to partially replace the binder (typically cement) in mortars manufacture, it can be find several advantages regarding to its durability, and consequently provide significant decrease in the use of cement with obvious effects on natural resources saving and the reduction of the greenhouse gases emissions caused by the cement manufacturing. Additionally, is minimized the waste disposal in landfills and thus reduced the risk of soil, air and water pollution. However, in traditional mortars of hydraulic binders is verified that the lower the proportion of cement, the lower the mechanical strength (flexural and compression), which is expected to happen with partial replacement of cement with a residue.

With the present work is intended to assess the performance of the fly ashes and paper mill sludges blended with cement for application in construction. With an experimental campaign which relies in the implementation of a wall to perform pull-off tests for assessing the adhesive strength, it is intended to evaluate the adhesive capacity of the materials under study. Further, the additional mechanical properties will be evaluated with flexural and compression strengths of mortars with different compositions. The sustainability of the materials will also be checked with leaching tests in raw materials and final mortars, in the hardened state.

\section{MAterials AND MethodS}

In fly ashes, pulp mill sludges and cement, moisture, organic matter, ashes were valued by gravimetric methods. After dried, a representative amount of each sample was chemically characterized following the European Standard EN 12457-4:2002, the leaching compliance test for leaching of granular waste materials and sludges. The parameters evaluated were chosen according to the main characteristics expected taking into account the wastes source, namely, $\mathrm{pH}$, conductivity, redox potential, sulfates and chloride.

The mortars were prepared and tested according to the procedure set out in NP EN 196-1: 1996, with specific adaptations. For the preparation of mortars several mixtures containing different weight percentages of residue were prepared (Table I). The water/cement ratio used was 0.4 after previous evaluation of the amount with suitable workability for this purpose. The prismatic specimens had dimensions of $40 \times 40 \times 160 \mathrm{~mm} 3$ and were placed in a wet controlled atmosphere. The mold release of the specimens was performed after $48 \mathrm{~h}$ ensuring sufficient strength to handle without risk of damaging. The specimens were fully immersed in water at $20 \pm 1{ }^{\circ} \mathrm{C}$ thereby providing a suitable curing condition and were removed from the water seven days 
after mixing to achieve the mechanical tests described in NP EN 196-1.

TABLE I: COMPOSITIONS OF TESTED MORTARS

\begin{tabular}{lccccc}
\hline \multirow{1}{*}{$\begin{array}{c}\text { Mortars } \\
\text { Identification }\end{array}$} & Cement & $\begin{array}{c}\text { Hydraulic } \\
\text { Lime }\end{array}$ & Ashes & $\begin{array}{c}\text { Pulp } \\
\text { mill }\end{array}$ & Water \\
\cline { 2 - 6 } C 100 & 1000 & 0 & 0 & 0 & 400 \\
C90 - A10 & 900 & 0 & 100 & 0 & 400 \\
C80 - A20 & 800 & 0 & 200 & 0 & 400 \\
C90 - PM10 & 900 & 0 & 0 & 100 & 400 \\
C80 - PM20 & 800 & 0 & 0 & 200 & 400 \\
C50 - HL50 & 500 & 500 & 0 & 0 & 400 \\
C45 - HL45 -A10 & 450 & 450 & 100 & 0 & 400 \\
C45 - HL45 - & 450 & 450 & 0 & 100 & 400 \\
PM10 & & & & & 0 \\
\hline \hline
\end{tabular}

C: cement; A: ashes; PM: pulp mill; HL: hydraulic lime

To determine flexural strength, the European Standard 1015-11: 1999 describes the determination of flexural strength in $40 \times 40 \times 160 \mathrm{~mm}^{3}$ specimen under three -point bending. This prompts tensile failure at approximately midspan, wasting two large segments of mortar. To evaluate the flexural strength a Multitester equipment was used. The half-prisms resulting from the bending test were utilized for the compressive strength after grinding the samples to $40 \times 40$ $\mathrm{mm}^{2}$, using the same equipment. Leaching tests were carried out for crushed samples after 28 days, in accordance with the standard procedures mentioned above.

For the pull-off tests of ceramics, a $3.5 \mathrm{~m}$ large and $60 \mathrm{~m}$ height wall was built with 21 thermal briks of $20 \mathrm{~cm}$ thickness, following a traditional procedure. Ceramics with $15 \times 15 \mathrm{~cm}^{2}$ and $7 \mathrm{~mm}$ thick were applied with the bonding mortars under evaluation. The pull-off strength was tested following the methodology specified in EN 1015-12: 2000 after 60 days of application (Fig. 1). The maximum adhesive strength and the type of rupture were assessed.

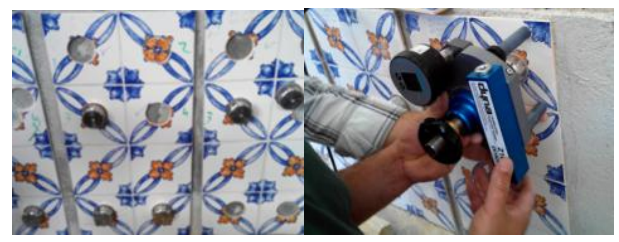

(a) (b)

Fig. 1. Wall with ceramic and the metallic disks (a) to perform the pull-off strength test (b).

\section{RESULTS}

\section{A. Chemical Characterization}

The wastes used in this study result from industrial activity in the region. The fly ashes are a byproduct, resulting from the cleaning of exhaust emissions of a thermoelectric plant that produces energy from forest biomass, namely trees and forestry waste, including material from driving operations, thinning and pruning, branches, pecking, stumps, leaves, roots and bark. In agreement with the Portuguese and European law, Portaria n ${ }^{\circ}$ 209/2004 March 3rd, that establish a list of wastes, this waste is classified as 100103 - peat and (untreated) wood fly ash. The constituents of biomass ashes are quite diverse depending on the type of original material, the type of soil and crop. In general, the major inorganic elements present in the ash are calcium $(\mathrm{Ca})$, potassium $(\mathrm{K})$, sodium $(\mathrm{Na})$, silicon $(\mathrm{Si})$ and phosphorus $(\mathrm{P})$.

Lime mud is an inorganic sludge separated from the chemical recovery cycle. These sludges are normally landfilled, after dewatering and drying. According with the European list of wastes, the lime mud is classified as 030309 - wastes of lime sludge. In Table II is an indication of the typical chemical composition of lime mud.

\begin{tabular}{|c|c|c|}
\hline \multicolumn{3}{|c|}{ FROM [8]) } \\
\hline Component & Average [\%] & Range [\%] \\
\hline $\mathrm{CaCO}_{3}$ & 95.00 & $92-97$ \\
\hline $\mathrm{MgO}$ & 1.04 & $0.4-1.6$ \\
\hline $\mathrm{SiO}_{2}$ & 0.50 & $0.1-0.4$ \\
\hline $\mathrm{Al}_{2} \mathrm{O}_{3}$ & 0.14 & $0.05-0.4$ \\
\hline $\mathrm{Fe}_{2} \mathrm{O}_{3}$ & 0.05 & $0.01-0.4$ \\
\hline $\mathrm{P}_{2} \mathrm{O}_{6}$ & 0.86 & $0.2-1.4$ \\
\hline $\mathrm{Na}_{2} \mathrm{O}$ & 1.14 & $0.5-1.6$ \\
\hline $\mathrm{K}_{2} \mathrm{O}$ & 0.09 & $0.04-0.12$ \\
\hline $\mathrm{SO}_{3}$ & 0.91 & $0.3-2.5$ \\
\hline
\end{tabular}

In order to evaluate further environmental behavior of the mortars, a previous wastes characterization was done (Table III) with proximate analysis as well as main leaching components evaluation. These parameters are considered of great importance for further mortars stability estimation.

TABLE III: CHEMICAL CHARACTERIZATION OF THE MATERIALS PREVIOUS TO MORTAR PREPARATION

\begin{tabular}{cccc}
\hline \hline & Fly ashes & $\begin{array}{c}\text { Pulp mill } \\
\text { sludge }\end{array}$ & Cement \\
\hline Moisture [\%] & 0.03 & 33.7 & 0.41 \\
Organic matter [\%] & 0.27 & 0.83 & n.d. \\
Ashes [\%] & 99.7 & 99.2 & 100 \\
pH & 11.6 & 10.5 & 12.6 \\
$\begin{array}{c}\text { Condutivity [ms/cm] } \\
\text { Sulfate [mg/kg dry } \\
\text { waste] }\end{array}$ & 1.19 & 3.02 & 2.50 \\
$\begin{array}{c}\text { Chloride [mg/kg dry } \\
\text { waste] }\end{array}$ & 911.8 & 2584 & 1027 \\
\hline \hline n.d. - not detected. & 245.4 & 18.6 & 526.4 \\
\hline
\end{tabular}

The inorganic features are visible regarding the high percentage of ashes and very low presence of organic matter. The moisture is high in the lime mud, suggesting the need to previous dry before mortar preparation. Ashes and lime mud have similar $\mathrm{pH}$, alkaline, and conductivity of cement. In fact the chemical composition of the three materials has some resemblance suggesting that the chemical reactions between the materials and water are similar. The reactions between water and the different metal oxides of the cement allow that Portland cement achieve it strength. None of the wastes is considered to be hazardous as expected by the wastes classification but also according with Table II from ANEX IV from the Decreto Lei $\mathrm{n}^{\circ} 183 / 2009$, August 10th, that transposes into internal law Directive 1999/31/EC of the Council of April 26th. Although the sulfate content is rather high it may still be considered not hazardous. This should be 
taking into account in the final mortars chemical characterization to evaluate the decrease in the leachability of this compound in the hardened specimens (Table IV). In the mortars after 28 days the sulfate leached decrease significantly. Is also important to note that hydroxyl, chloride and other dissolve ions, responsible for the conductivity, decreased in the leachate, suggesting there stabilization inside the solidified structures. This composition has as main issue the ability for future structures corrosion, but the levels found are much less than the defined in NP EN 206: 2007, which establishes the maximum value of $1.0 \%$ for chloride content in concrete.

TABLE IV: CHEMICAL CHARACTERIZATION OF THE MORTARS AFTER 28 DAYS OF CURING TIME

\begin{tabular}{lccccc}
\hline $\begin{array}{c}\text { Mortars } \\
\text { Identification }\end{array}$ & $\mathrm{pH}$ & Condutivity & $\begin{array}{c}\text { Redox } \\
\text { Potencial }\end{array}$ & $\begin{array}{c}\text { Sulfates } \\
\left(\mathrm{SO}_{4}{ }^{2-}\right) \\
{[\mathrm{mg} / \mathrm{kg}} \\
\text { dry } \\
\text { mass }]\end{array}$ & $\begin{array}{c}\text { Chloride } \\
\left(\mathrm{Cl}{ }^{-}\right) \\
{[\mathrm{mg} / \mathrm{kg}} \\
\text { dry } \\
\text { mass }]\end{array}$ \\
\hline C 100 & 12.06 & 2.05 & -7.60 & 67 & 496 \\
C90 - A10 & 12.02 & 1.83 & 2.55 & 30 & 261 \\
C80 - A20 & 11.98 & 1.67 & 10.05 & $<\mathrm{DL}$ & 223 \\
C90 - PM10 & 12.01 & 1.79 & 9.65 & $<\mathrm{DL}$ & 236 \\
C80 - PM20 & 11.99 & 1.78 & 14.80 & $<\mathrm{DL}$ & 261 \\
C50 - HL50 & 12.11 & 2.31 & 11.35 & $<\mathrm{DL}$ & 347 \\
C45 - HL45 & 12.01 & 2.01 & 0.35 & 24 & 236 \\
-A10 & 12.03 & 2.23 & 1.00 & 46 & 310 \\
C45 - HL45 - & 12.0310 & & & & \\
PM10
\end{tabular}

$<\mathrm{DL}-$ inferior to the detection limit.

The mortars chemical behavior after 28 days cannot be considered to be reasonable different among different mixtures, although some reduction of leaching compounds is noticed: in the redox potential, conductivity and even in chloride, with the last being strongly related. The former indicates a slight change in the oxidant medium, from reducing to oxidant, with eventual effects in the materials corrosion process, but the values are much too close to represent an evidence.

\section{B. Mechanical Strength}

The flexural strength was evaluated in prismatic specimens and the compressive strength in cubic specimens. Results are shown in Fig. 2.

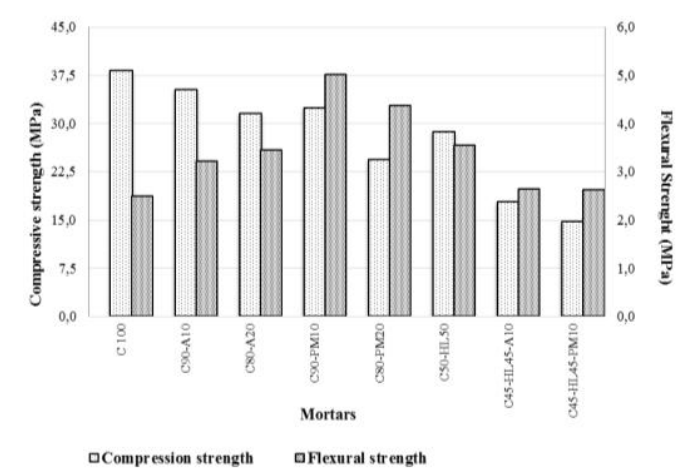

Fig. 2. Comparative mechanical strength, compressive and flexural, of mortars done with diferent amounts of wastes.

Flexural strength was higher in mortars with $10 \%$ of pulp mill sludge. Interestingly, the addition of this sludge and fly ashes increases the flexural strength of the mortars comparing with the ones prepared only with cement. An increase of ashes percentage enhances the mortars strength, in the range studied, but the increase of sludges tends to instill the opposite performance.

In the specimens with hydraulic lime addition for cement substitution (C45-HL45-A10 and C45-HL45-PM10), the strength decreased, and showed similar behaviour for ashes and pulp mill sludges. We may conclude that the carbonate characteristic of pulp mill improves the hardening of cement during the chemical reactions observed during hydration. On the other hand, the compressive strength is higher in specimens done only with cement, although the wastes addition does not have an important influence in the compressive strength behavior. Only high percentage substitution of cement by hydraulic lime has a significant effect. The composition of pulp mill (Table I) and ashes Zhu et al. [9], namely the content of calcium, siliceous and aluminum represent the ability of these materials to have a similar role as cement in the hydration process. It is known that changing the proportion of each of the constituent compounds in the cement, as well as other factors such as grain size, it is possible to make different types of cement to suit several construction needs. Therefore, the strength observed is within the usual commercial cement types.

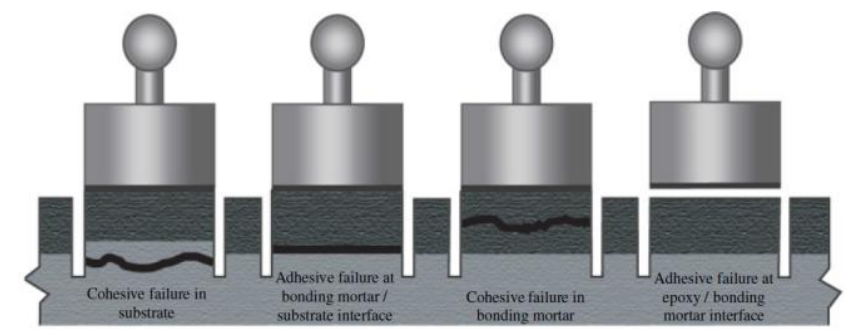

Fig. 3. Pull-off test failure modes (adapted from [10]).

As the main purpose was to evaluate the ability to use the new materials in the application of ceramics, as bonding mortars, assays were carried out according with EN 1015-12: 2000. The adhesion pull-off test intends to determine the force required to pull a $50 \mathrm{~mm}$ diameter metallic disk previously bonded to the support. Several tests were conducted to determine the medium adhesion strength and failure modes of each mixture. According to EN 1015-12: 2000 and Ramos et al. [11], the four failure modes can be classified as adhesive failure at epoxy/bonding mortar interface, cohesive failure in bonding mortar, adhesive failure at bonding mortar/substrate interface and finally the cohesive failure in substrate, as shown in Fig. 3.

After each test, the strength of maximum adhesive strength (Fig. 4) was registered and analyzed the corresponding type of failure (Table V).

The appearance of the metallic insert disks after the pull-off was observed for each tested material. It was found that almost all cement-based adhesives exhibit the same type of rupture in the two pre-cuts, except for the C45-HL45-A10 and C45-HL45-PM10. Only in these mixtures was observed that some of the plaster mortar (support) shaft along with the metallic disk, therefore, showing a cohesive rupture at support. 
TABLE V: TyPe OF FAILURE FOR THE CERAMIC-BONDING MORTAR

\begin{tabular}{lll}
\hline \hline Mortars Identification & \multicolumn{1}{c}{ Ceramic Pre-cut } & \multicolumn{1}{c}{ Ceramic Pre-cut + Bonding mortar } \\
\hline C 100 & cohesive failure in bonding mortar & cohesive failure in bonding mortar \\
C90-A10 & cohesive failure in bonding mortar & cohesive failure in bonding mortar \\
C80-A20 & adhesive failure at epoxy/bonding mortar interface & adhesive failure at epoxy/bonding mortar interface \\
C90-PM10 & adhesive failure at epoxy/bonding mortar interface & adhesive failure at epoxy/bonding mortar interface \\
C80-PM20 & adhesive failure at epoxy/bonding mortar interface & adhesive failure at epoxy/bonding mortar interface \\
C50-HL50 & cohesive failure in bonding mortar & cohesive failure in bonding mortar \\
C45-HL45-A10 & cohesive failure in substrate & adhesive failure at epoxy/bonding mortar interface \\
C45-HL45-PM10 & cohesive failure in substrate & adhesive failure at epoxy/bonding mortar interface \\
\hline \hline
\end{tabular}

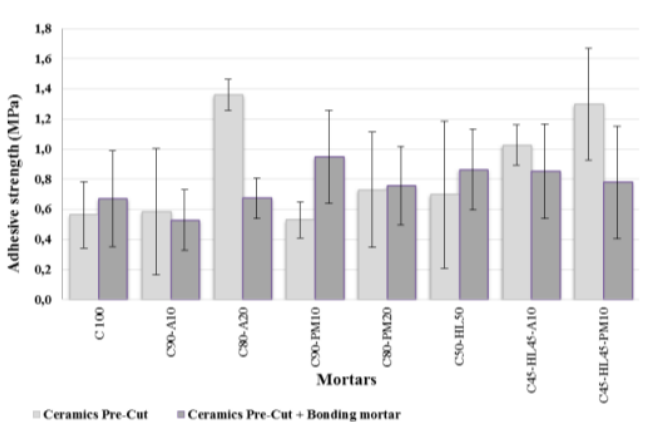

Fig. 4. Adhesive strength of the different mortars.

The failure mode that showed more commonness was the cohesive failure in bonding mortar, meaning that the adhesion of the bonding mortar to the ceramic is the most fragile element of the connection interface and that the mortars prepared with $10 \%$ of ashes had no different response than the traditional bonding mortar.

\section{CONCLUSION}

It was described the experimental program conducted with 8 bonding mortars. To carry out the campaign, was built a masonry wall with application of mortars. It was intended to evaluate the adhesion of these materials by running the pull-off test of ceramics. Similar behaviour was assessed with the different bonding mortars. In parallel with this study, we proceeded to analyze the mechanical performance of the mortars through flexural and compressive strength. The flexural strength had higher values when compared with cement, especially when 10 and $20 \%$ of cement was replaced by pulp mill sludge, but the compressive strength slightly decrease with the addition of both wastes. The chemical stability of the mortars after 28 days of aging showed that all the chemical species tend to be stabilized inside the solid structure, with a decrease of all the parameters tested. Although very promising results were achieved, further studies are needed to evaluate the ability to prepare and classify an eco-material with these wastes for specific preparation of bonding mortars.

\section{ACKNOWLEDGMENT}

The authors thank to Instituto Politécnico de Viseu (IPV), the Center for Studies in Education, Technologies and Health (CI\&DETS) and the Portuguese Foundation for Science and Technology (FCT).

\section{REFERENCES}

[1] R. Nowosielski, A. Kania, and M. Spilka, "Development of ecomaterials and materials technologies," Journal of Achievements in Materials and Manufacturing Engineering, vol. 21, pp. 27-30, 2007.
[2] Pappu, M. Saxena, and S. R. Asolekar, "Solid wastes generation in India and their recycling potential in building materials," Building and Environment, vol. 42, pp. 2311-2320, 2007.

[3] O. Kayali, "Fly ash lightweight aggregates in high performance concrete," Construction and Building Materials, vol. 22, pp. 2393-2399, 2008.

[4] F. Castro and T. Teixeira, "Incorporation of industrial wastes from thermal processes in cement mortars," Congreso Internacional De Metalurgia Y Materiales Sam-Conamet/Iberomat/Materia 2014, Santa Fe, Argentina, 2014.

[5] C. C. Ban and M. Ramli, "The implementation of wood waste ash as a partial cement replacement material in the production of structural grade concrete and mortar: An overview," Resources, Conservation and Recycling, vol. 55, pp. 669-685, 2011.

[6] A. U. Elinwa, P. S. Ejeh, and A. M. Mamuda, "Assessing of the fresh concrete properties of self-compacting concrete containing sawdust ash," Construction and Building Materials, vol. 22, pp. 1178-1182, 2008.

[7] M. C. Monte, E. Fuente, A. Blanco, and C. Negro, "Waste management from pulp and paper production in the European Union," Waste Management, vol. 29, pp. 293-308, 2009.

[8] H. Tran, "Lime kiln chemistry and effects on kiln operations," Pulp \& Paper Centre and Department of Chemical Engineering and Applied Chemistry, University of Toronto, Canada, 2008.

[9] F. Zhu, M. Takaoka, K. Oshita, Y. Kitajima, Y. Inada, S. Morisawa, and H. Tsuno, "Chlorides behavior in raw fly ash washing experiments," Journal of Hazardous Materials, vol. 178, no. 1-3, pp. 547-552, 2010.

[10] DY-2 Pull-Off Tester. [Online]. Available: http://www.pcte.com.au/dy-2-pull-off-tester

[11] N. M. M. Ramos, M. L. Simões, J. M. P. Q. Delgado, and V. P. Freitas, "Reliability of the pull-off test for in situ evaluation of adhesion strength," Construction and Building Materials, vol. 31, pp. 86-93, 2012 .

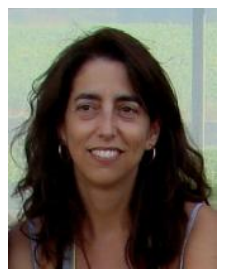

Isabel Brás was born in Anadia, Portugal. She is a chemical engineering with the master and Ph.D. degrees in environmental engineering from the Faculty of Engineering of University of Porto. She is currently a professor at Environmental Department of ESTGV, and is an investigator from the CI\&DETS of the Instituto Politécnio de Viseu. Her research interests include analytical / instrumental methods development for wastes characterization and methodologies for wastes valorization.

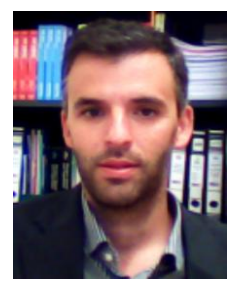

Ricardo Almeida was born in Viseu, Portugal. He is an assistant professor of civil engineering in the School of Technology \& Management at the Polytechnic Institute of Viseu and a researcher in the Building Physics Laboratory (CONSTRUCT-LFC) at Faculty of Engineering of University of Porto, Portugal. His research interests include construction materials, the hygrothermal performance, energy efficiency, and in

situ testing of buildings or building components and the dynamic simulation of energy in buildings.

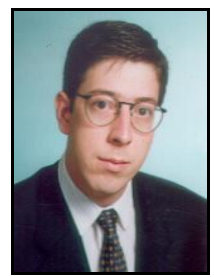

Paulo Costeira Silva was born in Viseu, Portugal. He is a civil engineer with the master and Ph.D. degrees in civil engineering from the Faculty of Engineering of University of Porto. He is currently a professor at Civil Engineering Department of ESTGV, and is an investigator from the CONSTRUCT at the Faculty of Engineering of University of Porto. His research interests include numerical modelling of concrete structures and strengthening of concrete structures with FRP materials. 